\title{
Description of Lutzomyia (Helcocyrtomyia) herreri sp. nov. (Diptera, Psychodidae, Phlebotominae) from the South Peruvian Andes
}

Eunice A. Bianchi Galati ${ }^{1}$

Abraham G. Cáceres ${ }^{2}$

\begin{abstract}
A new species of phlebotomine, Lutzomyia (Helcocyrtomyia) herreri sp. nov., belonging to the series osornoi, from the Department of Puno, Peru, is described. Identification keys for both sexes of the species of this series are presented.
\end{abstract}

KeYwords. Lutzomyia (Helcocyrtomyia) herreri sp. nov.; Peruvian Andes; Phlebotominae; Psychodidae; taxonomy.

\section{INTRODUCTION}

During a research carried out in November 2000 in Sandia province, Puno Department, on the oriental slope of the Peruvian Andes, with the purpose of studying the phlebotomine sandfly fauna, a new species, described below, was captured.

\section{MATERIAL AND METHODS}

The specimens were captured with Shannon trap (SHANNON 1939) and human bait in a peridomiciliary environment. After clearing by the method described by FoRATTINI (1973) and mounted on microscope slides in NC medium (CERQUEIRA 1943), the specimens were measured with a Zeiss ${ }^{\circledR}$ eye-piece calibrated with a standard Zeiss ${ }^{\circledR}$ scale and drawn with the help of an Olympus ${ }^{\circledR}$ drawing attachment. The structural terminology, in general, follows MCALPINE (1981), but regarding some specific structures studied in phlebotomines it follows GALATI (1995). All measurements are given in micrometers, those in parentheses represent the average and standard deviations for the paratypes. The material is deposited in the entomological collection of the Instituto Nacional de Salud, Lima, Peru (INSL) and in the entomological collection of the Faculdade de Saúde Pública, Universidade de São Paulo, São Paulo, Brazil (FSP/ USP).

\section{Lutzomyia (Helcocyrtomyia) herreri sp. nov.}

(Figs. 1 - 18)

Holotype (male). Total body length 3,550. Predominantly pale brown, with mesonotum and basal part of thoracic pleurae dark brown.

Head (Fig. 1): length 440; width 380. Eye length 258; width 145 (frontal view). Interocular distance 100. Interocular sutures not united with the interantennal suture. Clypeus length 145 . Antennomere lengths: AIII 500, AIV 212, AV 202, AXV 70,AXVI 67. Antennal formula AIII-AXV 2; AXVI 0; AIII with the external ascoid placed more apically than the internal one; AIV with ascoids simple and short, the distal prolongation reaching the middle of the segment (Fig. 2). Papilla present in AV (Fig. 3); AXI-AXIII without papilla (Fig. 4). Palpal formula: 1.4.2.3.5, with the length of palpomeres: I 40, II 180, III 195, IV 120, V 310; Newstead spines on the median third of palpomere III (Fig. 5) and absent on palpomere II. Labrum-epipharynx 340 long.

Cervix. Ventrocervical sensillae present.

Thorax. Mesonotum length 670. Pleurae with 5, 6 proepimeral bristles and 16, 17 upper anepisternal bristles; presence of setae on the anterior katepisternum edge and absence of the suture between katepimeron and metepisternum. Wing length 2,690, width 888; length of the vein sections: alpha 780, beta 250 , gamma 390, delta 200, pi 50 and $\mathrm{R}_{5}$ 1,680. (Fig. 15). Length of

\footnotetext{
1. Departamento de Epidemiologia, Faculdade de Saúde Pública, Universidade de São Paulo. Av. Dr. Arnaldo 715, 01246-904 São Paulo-SP, Brazil. E-mail: egalati@usp.br

2. Instituto Nacional de Salud. Calle Capac Yupanqui, 1400, Lima 100 Peru and Instituto de Medicina Tropical "Daniel A. Carrion", Universidad Nacional Mayor de San Marcos. Lima, Peru. E-mail: acaceres31@hotmail.com
} 
femora, tibiae, basitarsi and tarsi II+III+IV+V: foreleg 1,050, 1,650, 1,140, 1,040; midleg 950, 1,820, 1,300, 1,090; hindleg 1,120, $2,140,1,440,1,180$.

Abdomen 1,743 long; tergites III - VII with tergal papillae. Terminalia (Fig. 16): gonostyle 220 long with 5 spines; these with the following disposition: two apical, the upper external on the sixth apical of the structure, the lower external and internal on the third apical of the structure, at the same level. Gonocoxite 367 long $\mathrm{x} 80$ wide, with a dense basal tuft having ca. 12-13 setae. Paramere: dorsal margin length 212 and ventral margin length 262; with basal part rectangular and apical digitiform, this covered by setae on the dorsal margin. Aedeagus: conical; dorsal margin length 160 and the ventral margin length 62. Lateral lobe 290 long and 33 wide in the middle of structure. Genital pump 125 long; piston length 102 and chamber length 40 . Genital filaments length 408 or $3.26 x$ length of the genital pump (Fig. 17); tips of filaments simple. Cercus 210 long.

Allotype. Total body length $c a$. 3,170 $(3,285 \pm 234 ; \mathrm{n}=8)$. General coloration as in the male.

Head (Fig. 6): length $500(492 \pm 15 ; \mathrm{n}=10)$; width $445(456 \pm$ $14 ; \mathrm{n}=9)$. Eye: length $260(255 \pm 9 ; \mathrm{n}=10)$; width, in frontal view, $145(149 \pm 3 ; n=10)$. Interocular sutures not united with the interantennal suture. Interocular distance $145(150 \pm 9 ; n=$ 10). Clypeus $170(166 \pm 7 ; \mathrm{n}=10)$ long. Flagellomere lengths: AIII $485(485 \pm 21 ; \mathrm{n}=10)$; AIV $210(211 \pm 14 ; \mathrm{n}=10)$; AV 195 $(201 \pm 13 ; \mathrm{n}=10) ; \operatorname{AXV} 70(73 \pm 4 ; \mathrm{n}=10) ; \operatorname{AXVI} 63(66 \pm 3 ; \mathrm{n}=$ 10); Antennal formula AIII -AXV 2; AXVI 0; AIII with the external ascoid implanted more apically than the internal one; AIV with simple and short ascoids, the distal prolongation exceeding the middle of the segment, but not reaching the level of the papilla (Fig. 7). Papilla present in AV (Fig. 8); AXI-AXIII without papilla (Fig. 9). Palpomere lengths: I $53(52 \pm 6 ; \mathrm{n}=10)$, II $250(237 \pm 13 ; n=10)$, III $245(241 \pm 14 ; n=10)$, IV $110(101 \pm 7$; $\mathrm{n}=10)$, V $308(301 \pm 26 ; \mathrm{n}=10)$. Palpal formula: 1.4.3.2.5. (1.4.(2.3).5; $\mathrm{n}=5 ; 1.4 .2 .3 .5 ; \mathrm{n}=4 ; 1.4 .3 .2 .5 ; \mathrm{n}=1$ ); PV/PIII rate $1.26(1.25 \pm 0.09 ; \mathrm{n}=10)$. Newstead's spines distributed from basal third to apical fourth of palpomere III (Fig. 10) and absent on the palpomere II. Labrum-epipharynx $520(489 \pm 23 ; \mathrm{n}=10)$ long. Cibarium (Fig. 13) with ca. 16 reduced anterior vertical teeth, four posterior teeth and lateral teeth also greatly reduced, pigment patch and posterior bulge well developed, arch incomplete. Pharynx (Fig. 13) unarmed. Labium with united sutures forming furca. Maxilla: lacinia (Fig. 12) with 10 (9-14; n $=4$ ) external teeth disposed in a longitudinal row (two longitudinal rows; the more internal one with 1-3 small teeth; $n$ $=6)$ and $c a .30(22-29 ; \mathrm{n}=10)$ internal teeth. Hypopharynx (Fig. 11) with $c a .22(21-25 ; \mathrm{n}=10)$ deep apicolateral teeth.

Cervix. Ventrocervical sensillae present.

Thorax. Mesonotum $720(715 \pm 37 ; \mathrm{n}=10)$ long. Pleurae with $3,4(1-7 ; n=10)$ proepimeral bristles and $16,17(15-21 ; n=$ 10) upper anepisternal bristles. Presence of the setae on the anterior katepisternum edge and absence of the suture between katepimeron and metepisternum. Wing: length 2,950 (2,896 \pm $150 ; n=10)$; width $930(944 \pm 48 ; n=10)$. Length of vein sections: alpha $820(825 \pm 38 ; \mathrm{n}=10)$, beta $270(285 \pm 25 ; \mathrm{n}=10)$, gamma $470(450 \pm 44 ; \mathrm{n}=10)$, delta $165(191 \pm 39 ; \mathrm{n}=10)$, pi -10 (varying from -40 to $30 ; n=10), R_{5} 1,750(1,784 \pm 90 ; n=10)$. (Fig. 14 ) Length of femora, tibiae, basitarsi and tarsi II+III+IV+V: foreleg $1,120(1,094 \pm 65 ; n=9) ; 1,670(1,608 \pm 105 ; n=9), 1,160$ $(1,156 \pm 89 ; \mathrm{n}=9) ; 1,110(1,067 \pm 53 ; \mathrm{n}=9)$, midleg $1,020(986 \pm$ $71 ; \mathrm{n}=10), 1,830(1,796 \pm 127 ; \mathrm{n}=10), 1,280(1,245 \pm 103 ; \mathrm{n}=10)$, $1,130(1,103 \pm 64 ; \mathrm{n}=10) ;$ hindleg $1,120(1,079 \pm 77 ; \mathrm{n}=7), 2,120$ $(2,144 \pm 116 ; \mathrm{n}=7), 1,450(1,424 \pm 95 ; \mathrm{n}=7), 1,260(1,174 \pm 78 ; \mathrm{n}$ $=7$ ).

Abdomen length $1,870(1,967 \pm 151 ; \mathrm{n}=10)$; tergite VIII with 4, 6 (2-10; $n=10)$ setae. Spermathecae (Fig. 18$)$ with $c a .17$ annuli $(15-20 ; \mathrm{n}=8), 45(46 \pm 5 ; \mathrm{n}=8)$ long $\times 8.5(8.6 \pm 0.3 ; \mathrm{n}=8)$ wide, smooth individual ducts, $116(101 \pm 10 ; \mathrm{n}=8)$ long $\mathrm{x} 2.1$ $(2.2 \pm 0.5 ; \mathrm{n}=8)$ wide; smooth common duct, $28(27 \pm 6 ; \mathrm{n}=8)$ long x $3.0(4.4 \pm 0.5 ; \mathrm{n}=8)$ wide. Cercus $188(172 \pm 5 ; \mathrm{n}=10)$ long.

Type material. Holotype male. PERU. Puno, Sandia province: Alto Inambari district, Camaron, 4.XI.2000, Shannon trap, 18:00-24:00 hours, Arias F. and Choque E. cols. (INSL); 6 female paratypes: same data as holotype (3 INSL, 3 FSP/USP). Allotype and 1 female paratype: Alto Inambari district, Palmera, 29.XI.2000, Shannon trap, 18:00-24:00 hours, Arias F. and Choque E. cols. (INSL) and 5 female paratypes: Pacaysuizo district (1,000 m a. s. 1.), 31.X. 2000, human bait, 18:00-20:00 hours, Arias F. and Choque E. cols. (3 INSL, 2 FSP/USP).

\section{TAXONOMICDISCUSSION}

Lutzomyia (Helcocyrtomyia) Barretto, 1962, having Phlebotomus peruensis Shannon, 1929 as the type species, was originally constituted by four species-groups: peruensis, oswaldoi, vexatrix and sanguinaria. THEODOR (1965) considered the oswaldoi group as a distinct taxon from the vexatrix group and this latter was divided into the series vexatrix and peruensis; the species belonging to sanguinaria group of BARRETTO (1962) were included in this latter series. Both, oswaldoi and vexatrix groups, were included in the genus Lutzomyia. Lewis et al. (1977) also adopted these groupings. Martins et al. (1978) followed Barretto (1962). Young \& Duncan (1994), regarding the oswaldoi group, followed THEODOR (1965) and adopted L. (Helcocyrtomyia) without separation into groups or series of species. GALATI (1995) also considered Helcocyrtomyia as a subgenus of Lutzomyia, but the series vexator and oswaldo $i$ were included in the genus Micropygomyia Barretto, 1962, belonging to the Sergentomyiina subtribe.

In accordance with GaLati (1995), L. (Helcocyrtomyia) may be characterised by having, in both sexes, the external ascoid in a more apical position than the internal one on the AIII, presence of papilla on $\mathrm{AV}$, presence of the ventrocervical sensillae and setae on the anterior edge of the katepisternum and the spines of the third posterior tarsomere implanted as verticil on several levels; the male with five spines on the gonostyle, the two external ones implanted isolately and the female with annulated spermathecae. So, the characteristics described for Lutzomyia herreri sp. nov. allow us to include it 

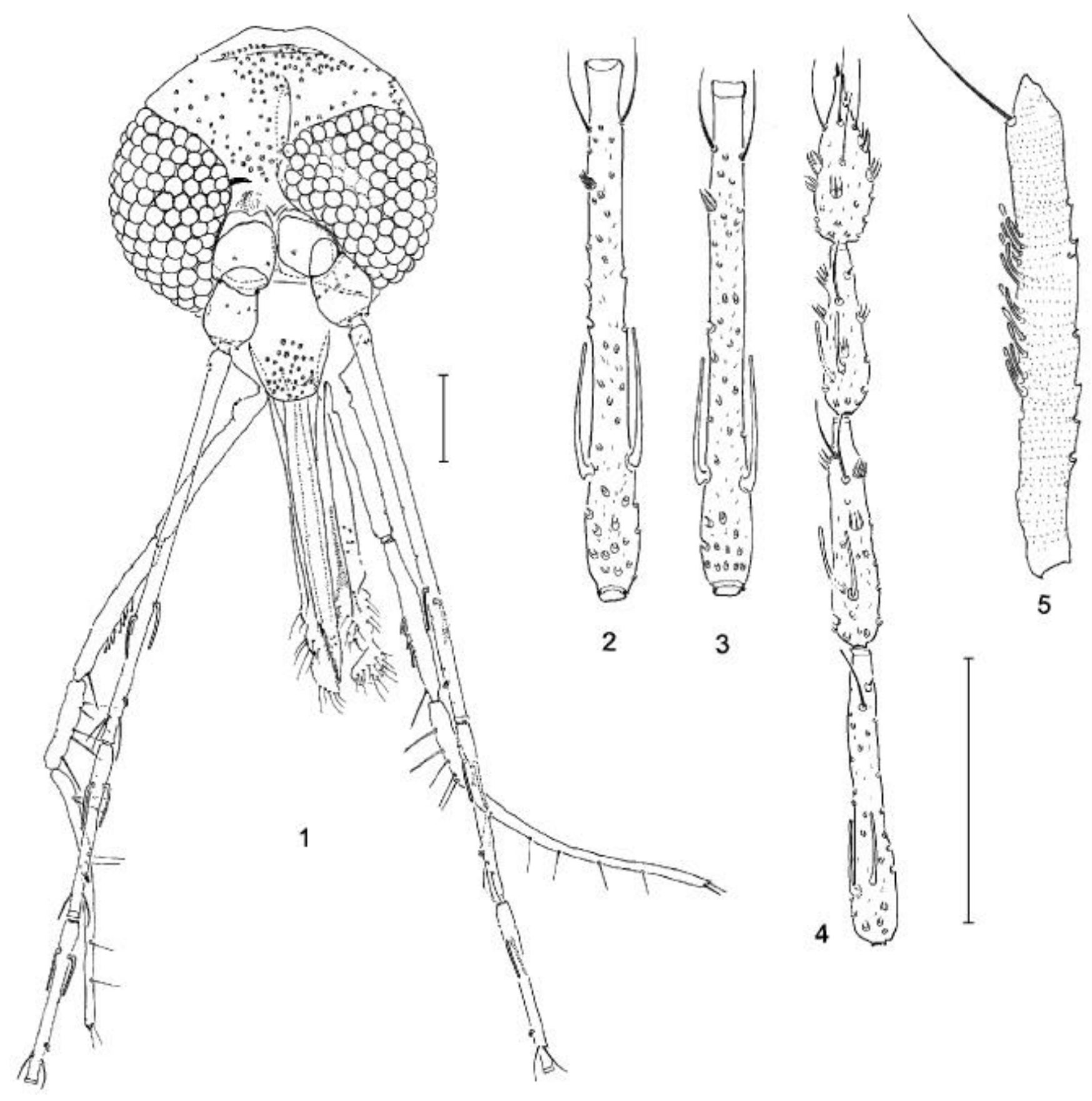

Figs. 1-5. Lutzomyia (Helcocyrtomyia) herreri sp. nov., holotype male. 1, head; 2, antennomere IV; 3, antennomere V; 4, antennomeres XIII - XVI; 5, palpomere III. Bar $=100 \mu \mathrm{m}$.

in L. (Helcocyrtomyia) and, within this subgenus, in the series osornoi, according to GALATI \& CÁcERES (1994), due to the presence in the terminalia of the male of a dense basal tuft with1213 setae on the gonocoxite and lateral lobe shorter than the gonocoxite; the $\mathrm{V}$ female palpomere being $1.25 \mathrm{x}$ longer than III and clypeus longer than $1 / 3$ of the head length. This series includes more 12 species, with a probable synonym; one species is known only by the female and two others only by the males; for one species, exists the suspicion that the female may have been described as belonging to another species: $L$. caballeroi Blancas, Cáceres \& Galati, 1989 (M/F); L. castanea Galati \& Cáceres, 1994 (M/F); L. ceferinoi (Ortiz \& Alvarez, 1963) (M/F?), the female of which was probably described by Young \& Morales 1987 as L. erwindonaldoi (Ortiz, 1978) (GALATI \& CÁCERES 1994); L. erwindonaldoi (M) [= L. larensis Arredondo, 1987 (MF); probable junior synonym (GALATI \& 

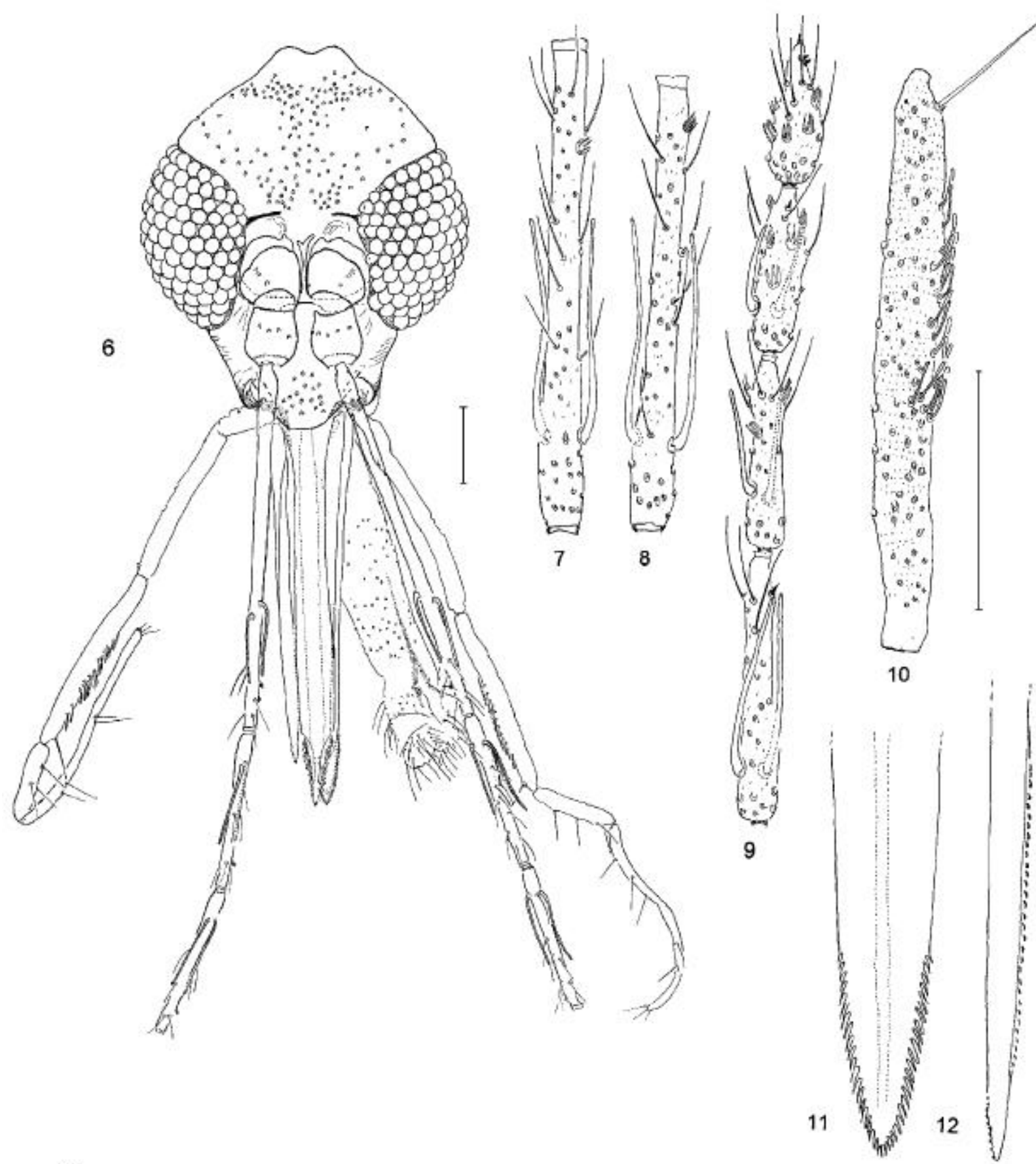

13

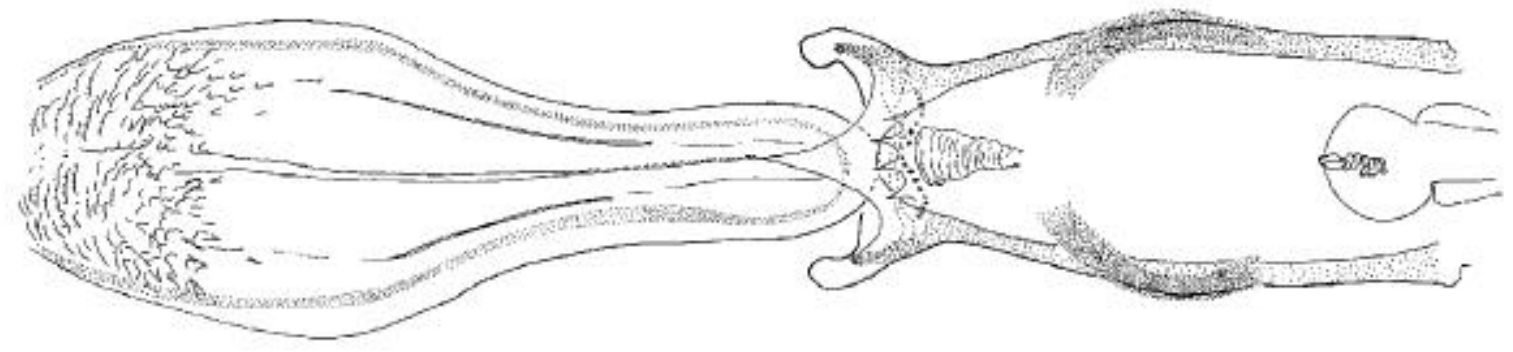

Figs. 6-13. Lutzomyia (Helcocyrtomyia) herreri sp. nov., allotype. 6, head; 7, antennomere IV; 8, antennomere V; 9, antennomeres XIII - XVI; 10, palpomere III; 11, hipopharynx; 12, lacinia; 13, cibarium and pharynx. Bar $=100 \mu \mathrm{m}$. 

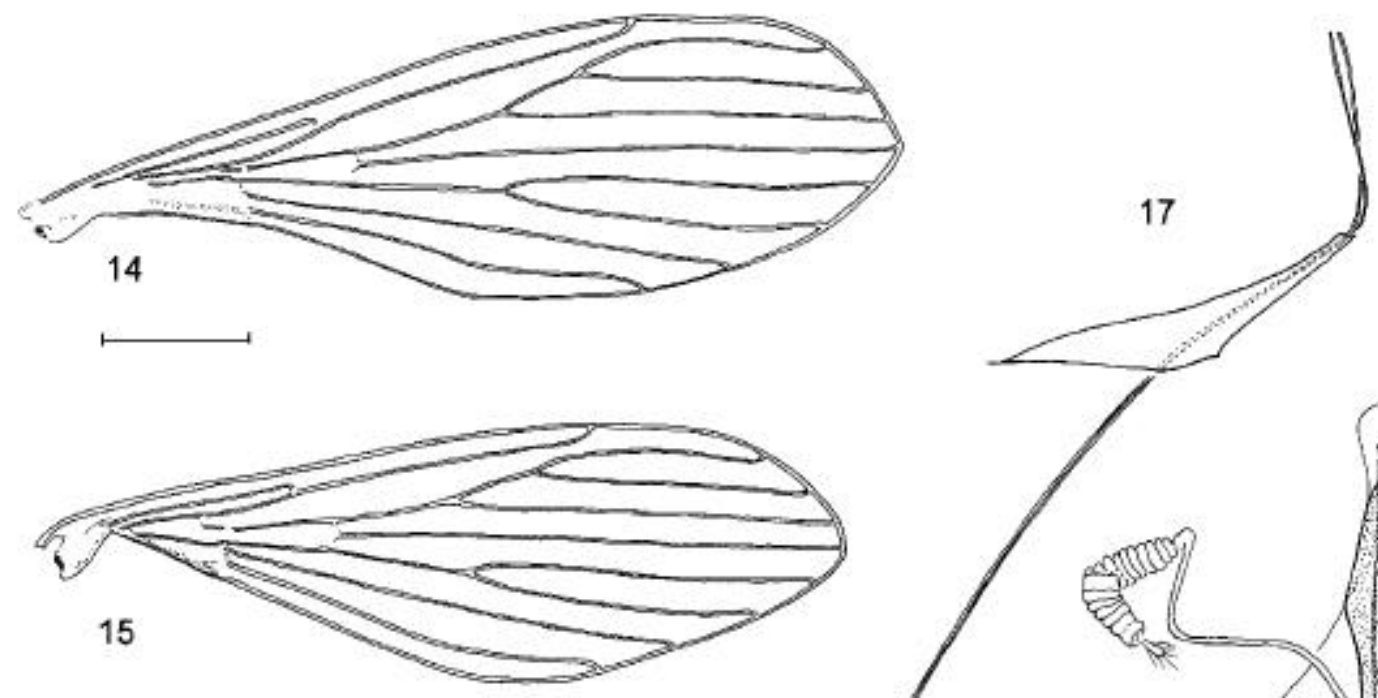

18

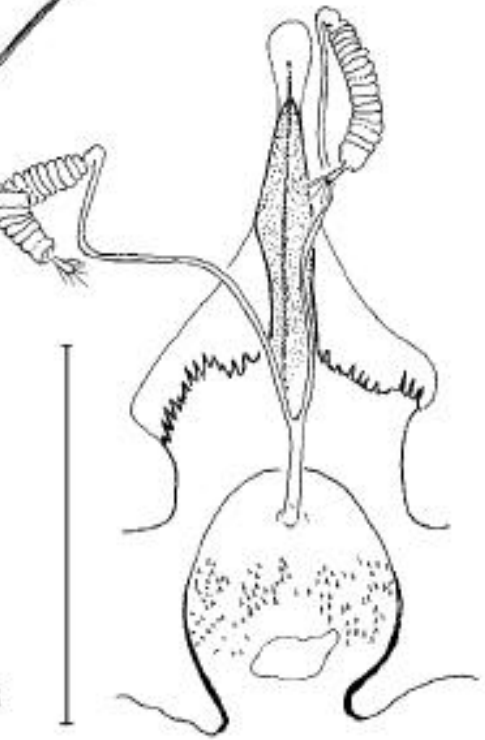

16

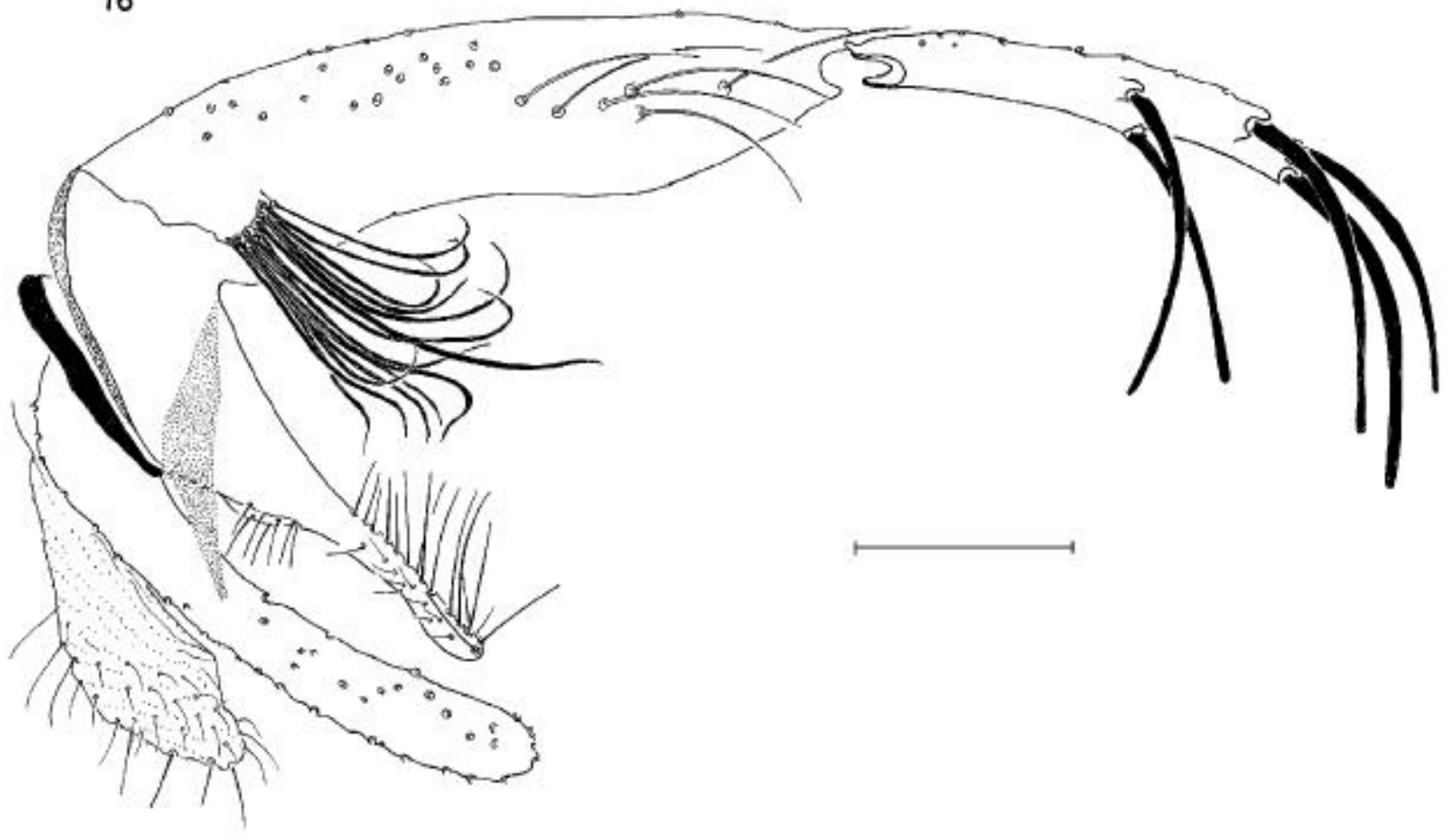

Figs. 14-18. Lutzomyia (Helcocyrtomyia) herreri sp. nov., 14, wing allotype; 15, wing holotype. Bar = 500 $\mu \mathrm{m}$. 16, holotype male, terminalia; 17, holotype male, aedeagus, genital pump and filaments; 18, allotype, genital fork and spermathecae. Bar $=100 \mu \mathrm{m}$. 
CÁCeres 1994)]; L. imperatrix (Alexander, 1944) (F); L. munaypata Ogusuku, Chevarria, Porras \& Pérez, 1999 (M/F); L. osornoi (Ristorcelli \& Van Ty, 1941) (M/F); L. quillabamba Ogusuku, Chevarria, Porras \& Pérez, 1999 (M/F); L. rispaili Torrez-Espejo, Cáceres \& Le Pont, 1995 (M), L. strictivilla Young, 1979 (M/F) and L. wattsi Fernández, Carbajal, Astete \& Wooster, 1998 (M).

Both sexes of $L .(H$.$) herreri sp. nov. may be distinguished$ from the other species of the series osornoi by the characteristics given in the identification keys presented below.

The sexes were associated by the concordance of genital characteristics, coloration pattern of the body and wing venation and because they were the only representatives of the series osornoi in the captures.

Etymology. The name L. herreri honours Dr. Aristides Herrer Alva, who dedicated part of his life to the study of human bartonellosis epidemiology in Peru. Further, he was the pioneer in leishmaniasis research in Peru and Panama.

Key for males of the series osornoi

1. Head length $\geq 500 \mu \mathrm{m}$; wing length $\geq 3.2 \mathrm{~mm}$ and gonocoxite $\geq 450 \mu \mathrm{m}$.

Head length $\leq 450 \mu \mathrm{m}$; wing length $\leq 2.7 \mathrm{~mm}$ and gonocoxite $\leq 400 \mu \mathrm{m}$

2(1). Wing venation: delta ca. $1 / 2$ of alpha

........ L. erwindonaldoi (Ortiz) L. larensis Arredondo

Wing venation: delta $\leq 1 / 4$ of alpha 3

3(2). Wing venation: delta ca. $1 / 6$ of alpha

........ L. wattsi Fernández, Carbajal, Astete \& Wooster

Wing venation: delta ca. $1 / 4$ of alpha .

4(3). Width of the digitiform part of the paramere equivalent to that of $2 / 3$ of the lateral lobe (the latter measured in its narrowest part)

L. caballeroi Blancas, Cáceres \& Galati

Width of the digitiform part of the paramere equivalent to that of the lateral lobe (the latter measured in its narrowest part) ...... L. osornoi (Ristorcelli \& Van Ty)

5(1). Wing venation: delta ca. $1 / 3$ of alpha and beta ca. $2 / 5$ of gamma.

Wing venation: delta ca. $1 / 4$ of alpha and beta ca. $3 / 5$ of gamma.

6(5). Gonocoxite tuft with 21 or less semi-foliaceous setae; paramere concave in the middle of the dorsal margin, thus curved in the direction of the gonocoxite ....... 7

Gonocoxite tuft with $c a$. 25 fine setae; paramere straight on dorsal margin . L. strictivilla Young

7(6). Gonocoxite tuft with 18-21 setae

L. rispaili Torrez-Espejo, Cáceres \& Le Pont

Gonocoxite tuft with $12-15$ setae ... L. munaypata Ogusuku, Chevarria, Porras \& Pérez

8(5). Gonocoxite tuft with $c a .30$ setae implanted in tubercle..
.. L. quillabamba Ogusuku, Chevarria, Porras \& Pérez

Gonocoxite tuft with 25 or less setae not implanted in tubercle. 9

9(8). Gonocoxite tuft with $c a .20$ setae with the basal wider than the apical ones ....... L. castanea Galati \& Cáceres

Gonocoxite tuft with ca. 9-14 setae 10

10(9). Gonocoxite tuft with subequal wide setae implanted in a circular non compact area

L. ceferinoi (Ortiz \& Alvarez)

Gonocoxite tuft implanted in a semilunar compact area L. herreri sp.nov.

Key for females of the series osornoi

1. Head length $\geq 580 \mu \mathrm{m} ; \mathrm{AIII} \geq 570 \mu \mathrm{m}$; wing length $\geq 3.5$ $\mathrm{mm}$

2

Head length $\leq 520 \mu \mathrm{m} ;$ AIII $\leq 530 \mu \mathrm{m}$; wing length $\leq 3.2$ $\mathrm{mm}$

.4

2(1). Wing venation: delta ca. $1 / 2$ of alpha

Wing venation: delta $\leq 1 / 4$ of alpha

L. larensis Arredondo

3(2). Pigmented area of cibarium twice as long as its basal part. Spermathecae: common duct $2 / 3$ of body length .....

L. caballeroi Blancas, Cáceres \& Galati

Pigmented area of cibarium four times as long as its basal part. Spermathecae: common duct $1 / 4$ of the body length ...... L. osornoi (Ristorcelli \& Van Ty)

4(1). Wing venation: delta/alpha ca. 0.4 .................................. 5

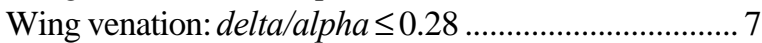

5(4). Wing venation: beta/gamma ca. 0.5

... L. munaypata Ogusuku, Chevarria, Porras \& Pérez

Wing venation: beta/gamma $\leq 0.4$ 6

6(5). AIII longer than the labrum-epipharynx, which is $c a .2$ times as long as the clypeus ....L. strictivilla Young AIII shorter than the labrum-epipharynx, which is $c a .2 .5$ times longer than the clypeus .. L. quillabamba Ogusuku, Chevarria, Porras \& Pérez

7(4). Wings: width ca. $1.15 \mathrm{~mm}$, alpha $1.17 \mathrm{~mm}$ and delta 0.34 $\mathrm{mm}$ L. imperatrix (Alexander) Wings: width $\leq 1.0 \mathrm{~mm}$, alpha $\leq 0.93 \mathrm{~mm}$ and delta $\leq 0.31$ $\mathrm{mm}$... .8

8(7). $\quad$ AIII $\leq 370 \mu \mathrm{m}$; labrum-epipharynx $\leq 410 \mu \mathrm{m}$ . L. ceferinoi (Ortiz \& Alvarez) AIII $\geq 400 \mu \mathrm{m}$; labrum-epipharynx $\geq 460 \mu \mathrm{m}$ .9

9(8). Pronotum and paratergite dark brown L. castanea Galati \& Cáceres Pronotum and paratergite light brown L. herreri sp. nov. 


\section{REFERENCES}

Barretto, M. P. 1962. Novos subgêneros de Lutzomyia França, 1924 (Diptera, Psychodidae, subfamília Phlebotominae). Revista do Instituto de Medicina Tropical de São Paulo 4(2): 91-100.

Cerqueira, N. C. 1943. Novo meio para a montagem de pequenos insetos em lâminas. Memórias do Instituto Oswaldo Cruz 39: 37-41.

Forattini, O. P. 1973. Entomologia Médica. IV. Psychodidae. Phlebotominae. Leishmanioses. Bartonelose. São Paulo, Edgard Blücher Ltda., 658p.

Galati, E. A. B. 1995. Phylogenetic systematics of Phlebotominae (Diptera, Psychodidae) with emphasis on American groups. Boletín de la Dirección de Malariología y Saneamiento Ambiental 35(Supl. 1): 133-142.

Galati, E. A. B. \& A. G. CÁceres. 1994. Descrição de Lutzomyia pallidithorax, sp. n. e de Lutzomyia castanea, sp. n. do Peru e análise cladística das séries do subgênero Helcocyrtomyia Barretto (Diptera, Psychodidae). Revista Brasileira de Entomologia 38(2): 471 488 .
Lewis, D. J.; D. G. Young; G. B. FAIRChILD \& D. M. Minter. 1977. Proposals for a stable classification of Phlebotomine sandflies (Diptera: Psychodidae). Systematic Entomology 2: 319-332.

Martins, A. V.; P. Williams \& A. L. Falcão. 1978. American Sand Flies. Rio de Janeiro, Academia Brasileira de Ciências, 195 p.

McAlpine, J. F. 1981. Morphology and terminology - Adults. p. 9-63. In: J. F. Mcalpine; B. V. Peterson; G. E. Shewell; H. J. Teskey; J. R. Vockeroth \& D. M. Wood. 1981. Manual of Nearctic Diptera. Ottawa, Research Branch Agriculture Canada, Monography 27, Vol. 1 .

Shannon, R. 1939. Methods for collecting and feeding mosquitos in jungle yellow fever studies. American Journal of Tropical Medicine and Hygiene 19: 131-148.

Theodor, O. 1965. On the classification of American Phlebotominae. Journal of Medical Entomology 2(2): 171-197.

Young, D. G. \& M. A. Duncan. 1994. Guide to the identification and geographic distribution of Lutzomyia sand flies in Mexico, the West Indies, Central and South America (Diptera: Psychodidae). Memoirs of the American Entomological Institute, 54: 1-881. 